\title{
Correction: European League Against Rheumatism/American \\ College of Rheumatology classification criteria for adult and juvenile idiopathic inflammatory myopathies and their major subgroups
}

Lundberg IE, Tjärnlund A, Bottai M, et al. 2017 European League Against Rheumatism/ American College of Rheumatology classification criteria for adult and juvenile idiopathic inflammatory myopathies and their major subgroups. Ann of Rheum Dis 2018;76:1955-64.

The sentence on page 1957, right column:

Probability of IIM including muscle biopsy=1/[1+exponential(5.33-score)]

or,

Probability of IIM without muscle biopsy=1/[1+exponential(6.49-score)]

should read as:

Probability of IIM without muscle biopsy=1/[1+exponential(5.33-score)]

or,

Probability of IIM including muscle biopsy=1/[1+exponential(6.49-score)]

(C) Author(s) (or their employer(s)) 2018. No commercial re-use. See rights and permissions. Published by BMJ.

Ann Rheum Dis 2018;77:e64. doi:10.1136/annrheumdis-2017-211468corr1

D) Check for updates 